\title{
Analisis Tingkat Kenyamanan Di DKI Jakarta Berdasarkan Indeks THI (Temperature Humidity Index)
}

\author{
Trinah Wati ${ }^{1}$ dan Fatkhuroyan ${ }^{2}$ \\ 1Pusat Informasi Perubahan Iklim, Badan Meteorologi Klimatologi dan Geofisika, email: trinah.wati@gmail.com \\ 2Pusat Penelitian dan Pengembangan, Badan Meteorologi Klimatologi dan Geofisika
}

\begin{abstract}
ABSTRAK
Fenomena iklim mempengaruhi kenyamanan fisiologis di daerah pemukiman. Analisa tingkat kenyamanan di DKI Jakarta dilakukan menggunakan THI (Temperature Humidity Index). Berdasarkan data iklim periode 1985 - 2012 stasiun Kemayoran, Tanjung Priok, Halim, Cengkareng dan Pondok Betung, hasil penelitian menunjukkan rata-rata prosentase tingkat kenyamanan harian dengan kategori tidak nyaman sebesar 22,1\% (81 hari per tahun), sebagian nyaman $71 \%$ (259 hari per tahun) dan nyaman 7,1\% (26 hari per tahun). Tingkat kenyamanan menunjukkan semakin ke tengah kota semakin besar prosentase tidak nyaman. Selama periode tersebut terjadi kecenderungan peningkatan indeks THI dengan signifikansi > 50\% menunjukkan tingkat kenyamanan di DKI Jakarta cenderung semakin tidak nyaman.
\end{abstract}

Kata kunci: tingkat kenyamanan, temperature humidity index, urban heat island

\begin{abstract}
Climate phenomenon affects physiological comfortableness in residential area. Analysis of thermal comfort level in DKI Jakarta were conducted using THI (Temperature Humidity Index). Based on climate data stations in Kemayoran, Tanjung Priok, Halim, Cengkareng dan Pondok Betung during 1985-2012 showed that the average percentage of daily thermal comfort level with categories uncomfortable were $22,1 \%$ (81 days per year), half comfortable $71 \%$ (259 days per year) and comfortable $7,1 \%$ (26 days per year). The study showed that the greater percentage uncomfortable level, the closer into the center of the city and during 1985 to 2012 the THI index tend to increasing with significant level more than $50 \%$ meant that the thermal comfort level tend to more uncomfortable.
\end{abstract}

Keywords: thermal comfort level, temperature humidity index, urban heat island

Citation: Wati, T dan Fatkhuroyan. (2017). Analisis Tingkat Kenyamanan Di DKI Jakarta Berdasarkan Indeks THI (Temperature Humidity Index). Jurnal Ilmu Lingkungan, 15(1), 57-63, doi:10.14710/jil.15.1.57-63

\section{Introduction}

DKI Jakarta sebagai kota terbesar se-Asia Tenggara memiliki jumlah penduduk sebanyak 10.177.924 jiwa (BPS, 2016). Urbanisasi dan pengembangan wilayah kota yang terus menerus tanpa diikuti oleh keseimbangan lingkungan menyebabkan permasalahan lingkungan di kota. Salah satunya adalah permasalahan pemanasan kota atau Urban Heat Island (UHI), penyebab UHI di Kota DKI Jakarta dapat disebabkan oleh peningkatan emisi CO2 (Rushayati dan Hermawan, 2013), Menurut Effendy (2007) faktor yang berkontribusi terhadap UHI wilayah JABODETABEK (Jakarta, Bogor, Tangerang dan Bekasi) antara lain berkurangnya Ruang Terbuka Hijau (RTH), peningkatan kendaraan bermotor dan perluasan wilayah urban.

Fenomena UHI di DKI Jakarta telah terjadi dengan peningkatan suhu di pusat kota dan menurun ke arah sub urban baik arah utara, selatan, barat maupun timur (Rushayati dan Hermawan, 2013; Maru dan Ahmad, 2014). Saat ini penilaian terhadap tingkat kenyamanan yang dirasakan manusia di wilayah perkotaan semakin menarik untuk dilakukan terkait oleh peningkatan UHI di perkotaan dan perubahan iklim (Honjo, 2009). Perubahan unsur iklim yaitu suhu udara yang semakin meningkat merupakan yang paling langsung dapat dirasakan dan berpengaruh terhadap tingkat kenyamanan manusia. Selain suhu udara, kenyamanan dipengaruhi parameter iklim lain dan subjek yang merasakan kenyamanan. Parameter iklim yang juga berpengaruh terhadap kenyamanan manusia adalah angin. Angin dapat membawa udara panas ke tempat lain mencampurkan antara udara panas dan udara dingin serta udara lembab dan udara kering (Lakitan 2002). Kondisi nyaman apabila sebagian energi manusia dibebaskan untuk kerja produktif dan upaya pengaturan suhu tubuh berada pada level minimal. Secara kuantitatif dinyatakan sebagai Temperature Humidity Index disingkat THI yang pertama kali ditemukan oleh Thom (1959) dan dimodifikasi oleh Nieuwolt (1977) untuk wilayah tropis. Selain THI 
beberapa rumus indeks kenyamanan lain yang sudah digunakan di berbagai tempat diantaranya : Discomfort Index, Effective Temperature (Griffiths 1966), Predicted Mean Vote, Wet Bulb Globe Temperature (Lemke dan Kjellstrom 2012), Relative Strain Index (Emmanuel 2005), Physiological Equivalent Temperature (Mayer \& Höppe, 1987) dan lain-lain. Masing-masing persamaan indeks kenyamanan tersebut memiliki batas kenyamanan yang berbeda-beda.

Pemanfaatan perhitungan THI adalah untuk perencanaan pengembangan tata kota yang hijau dan ramah lingkungan. Dalam iklim perkotaan, perancangan dan arsitektur bangunan kota telah memfokuskan pada kenyamanan manusia/bioklimat (Emmanuel, 1993; 1997; Mertens, 1999). Indeks kenyamanan juga merupakan indikator untuk perancangan bangunan tempat bekerja sehingga mempermudah reorganisasi, perubahan atau strategi penempatan alat baru dan untuk peningkatan kenyamanan pekerja di tempat bekerja (Talaia, 2013).

Tujuan dari penelitian ini adalah untuk mengetahui tingkat kenyamanan di DKI Jakarta secara harian dan kecenderungan tingkat kenyamanan dari tahun ke tahun menggunakan indeks kenyamanan THI dengan batas kenyamanan berdasarkan Nieuwolt (1977) dan Emmanuel (2005) yang dimodifikasi untuk iklim tropis (Effendy, 2007).

\section{Metode}

Data yang digunakan dalam penelitian ini adalah data suhu udara dan kelembapan udara relatif harian tahun 1985 - 2012 di stasiun meteorologi Badan Meteorologi Klimatologi dan Geofisika (BMKG) Kemayoran, Tanjung Priok, Halim Perdanakusuma, Cengkareng (Bandara Soekarno-Hatta) dan Pondok Betung. Letak geografis dan posisi stasiun meteorologi dapat dilihat pada Tabel 1dan Gambar 1.

\section{Analisis Tingkat Kenyamanan}

Analisa tingkat kenyaman dinyatakan dalam indeks kenyamanan yaitu Temperature Humidity Indeks (THI) merupakan suatu indeks dengan satuan derajat celsius sebagai besaran yang dapat dikaitkan dengan tingkat kenyamanan yang dirasakan populasi manusia di wilayah perkotaan.

Tabel 1. Letak geografis stasiun meteorologi lokasi penelitian

\begin{tabular}{|c|c|c|c|c|}
\hline No & $\begin{array}{c}\text { Nama } \\
\text { Stasiun }\end{array}$ & Lintang & Bujur & $\begin{array}{c}\text { Elevasi } \\
\text { (m) }\end{array}$ \\
\hline 1 & $\begin{array}{c}\text { Soekarno } \\
\text { Hatta } \\
\text { Cengkareng }\end{array}$ & -6.11667 & 106.65000 & 8 \\
\hline 2 & Kemayoran & -6.18333 & 106.83333 & 4 \\
\hline 3 & $\begin{array}{l}\text { Pondok } \\
\text { Betung } \\
\text { Ciledug }\end{array}$ & -6.18333 & 106.83620 & 26 \\
\hline 4 & $\begin{array}{l}\text { Tanjung } \\
\text { Priok }\end{array}$ & -6.10000 & 106.86667 & 2 \\
\hline 5 & $\begin{array}{l}\text { Halim } \\
\text { Perdana } \\
\text { Kusuma }\end{array}$ & -6.25000 & 106.90000 & 26 \\
\hline
\end{tabular}


44 kecamatan dan 267 kelurahan. Propinsi ini dibagi menjadi lima kota dan satu kabupaten yaitu Jakarta Timur, Jakarta Barat, Jakarta Pusat, Jakarta Utara, Jakarta Selatan dan Kabupaten Kepulauan Seribu seperti pada Gambar 1 (BPS, 2016). Temperatur Provinsi DKI Jakarta pada tahun 2015 tertinggi di bulan Oktober $(30,210 C)$ dan terendah di bulan Februari (27,76 OC), dengan kelembaban 54 sampai 98 persen. Curah hujan bulanan tertinggi di bulan Februari (639 mm) dan terendah di bulan Juli (1 mm).

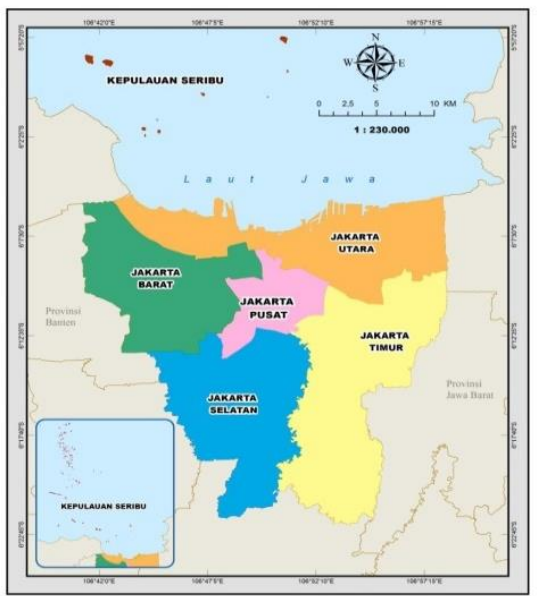

Gambar 2. Peta Wilayah DKI Jakarta (sumber: BPS, 2016)

\section{Tingkat Kenyamanan di DKI Jakarta}

Analisis tingkat kenyamanan di DKI Jakarta menggunakan Nieuwolt (1977) menggunakan data suhu dan kelembaban relatif rata-rata harian pada lima stasiun meteorologi BMKG. Berdasarkan perhitungan diperoleh prosentase frekuensi kejadian tingkat kenyamanan yang di kategorikan pada tiga tingkat kenyamanan yaitu Nyaman, Sebagian Nyaman dan Tidak Nyaman seperti pada tabel 2 dan Gambar 3. Tingkat kenyamanan harian di Kemayoran yang berada di Jakarta Pusat menunjukkan kategori nyaman sebesar 3,5\% atau 13 hari/tahun, sebagian nyaman $64,2 \%$ atau 234 hari/tahun dan tidak nyaman 32,3 \% atau 118 hari/tahun (gambar 3a). Sedangkan di Tanjung Priok yang berada di Jakarta Utara menunjukkan tingkat kenyamanan kategori nyaman sebesar 2,8\% atau 10 hari/tahun, sebagian nyaman $56,5 \%$ atau 207 hari/tahun dan $40,6 \%$ atau 148 hari/tahun (gambar 3b). Stasiun Halim yang berada di Jakarta Timur kategori nyaman selama 28 tahun lebih tinggi dibandingkan dengan stasiun lainnya yaitu sebesar $11,2 \%$ atau 41 hari/tahun, sebagian nyaman $79 \%$ atau 288 hari dan tidak nyaman paling rendah dibandingkan stasiun lainnya sebesar 9,2\% atau 34 hari/tahun (gambar 3c).

Tabel 2. Prosentase tingkat kenyamanan harian di DKI Jakarta periode 1985-2012

\begin{tabular}{|c|c|c|c|c|c|c|c|}
\hline \multirow{2}{*}{$\mathrm{THI}\left({ }^{\circ} \mathrm{C}\right)$} & \multirow{2}{*}{ Kategori } & \multicolumn{6}{|c|}{ Prosentase (\%) } \\
\hline & & Kemayoran & Tanjung Priok & Halim & Cengkareng & Pondok Betung & Rata-rata \\
\hline $21-24$ & Nyaman $\left(21-24^{\circ} \mathrm{C}\right)$ & 3.5 & 2.8 & 11.2 & 8.3 & 9.7 & 7 \\
\hline $25-27$ & Sebagian Nyaman $\left(25-27^{\circ} \mathrm{C}\right)$ & 64.2 & 56.5 & 79.0 & 77.2 & 75.0 & 71 \\
\hline$>27$ & Tidak Nyaman $\left(>27^{\circ} \mathrm{C}\right)$ & 32.3 & 40.6 & 9.2 & 13.1 & 15.2 & 22 \\
\hline
\end{tabular}

Jakarta Selatan dalam hal ini diwakili oleh stasiun Pondok Betung menunjukkan tingkat kenyamanan dengan kategori nyaman sebesar 9,7\% atau 35 hari/tahun, sebagian nyaman $15,2 \%$ atau 274 hari dan tidak nyaman $15,2 \%$ atau 55 hari/tahun (gambar 3d). Sedangkan wilayah Jakarta Barat diwakili oleh stasiun Cengkareng menunjukkan tingkat kenyamanan dengan kategori nyaman sebesar $8,3 \%$ atau 30 hari, sebagian nyaman $77,2 \%$ atau 282 hari dan tidak nyaman sebesar $13,1 \%$ atau 48 hari (gambar 3e). Tingkat kenyamanan berdasarkan posisi stasiun menunjukkan semakin ke pusat kota tingkat kenyamanan semakin tidak nyaman.

Nilai THI bulanan rata-rata pada Gambar 4 menunjukkan pola bimodal dengan puncak pada bulan Mei dan Oktober, THI terendah terjadi pada bulan Januari dan Juli. Rata-rata THI tertinggi terjadi di stasiun Tanjung Priok dan terendah di Halim.

Berdasarkan gambar 5a-5e terjadi tren peningkatan nilai THI dari tahun 1985 hingga 2012, dengan peningkatan setiap tahunnya sebesar 0,04 oC di Kemayoran 0,03oC di tanjung Priok, sedangkan di Halim 0,03oC, 0,04oC di Cengkareng dan 0,05oC di Pondok Betung. Peningkatan tersebut terjadi secara signifikan dengan besarnya koefisien determinansi (R2 > 50\%) yang artinya data yang mewakili lebih dari $50 \%$. Masing-masing nilai koefisien determinansi yaitu 78\% di Kemayoran, 52\% di Tanjung Priok, 62\% di Halim, 57\% di Cengkareng dan 76\% di Pondok Betung.

Terjadinya kecenderungan peningkatan nilai THI salah satunya disebabkan oleh semakin tingginya laju perkembangan urbanisasi di wilayah perkotaan. Pada gambar 6 ditunjukkan perubahan tutupan lahan di wilayah JaBoDeTaBek hasil penelitian Rustiadi et al (2015) dari tahun 1972 hingga tahun 2012. Berdasarkan gambar 6 pada tahun 1972 lahan terbangun (warna merah) masih terkonsentrasi di DKI Jakarta dan meningkat pada tahun 1983 dari 6.500 ha pada tahun 1972 menjadi 12.000 ha. Pada tahun 1990 lahan terbangun di DKI Jakarta semakin melebar dan selama 1985 hingga 2012 wilayah DKI 


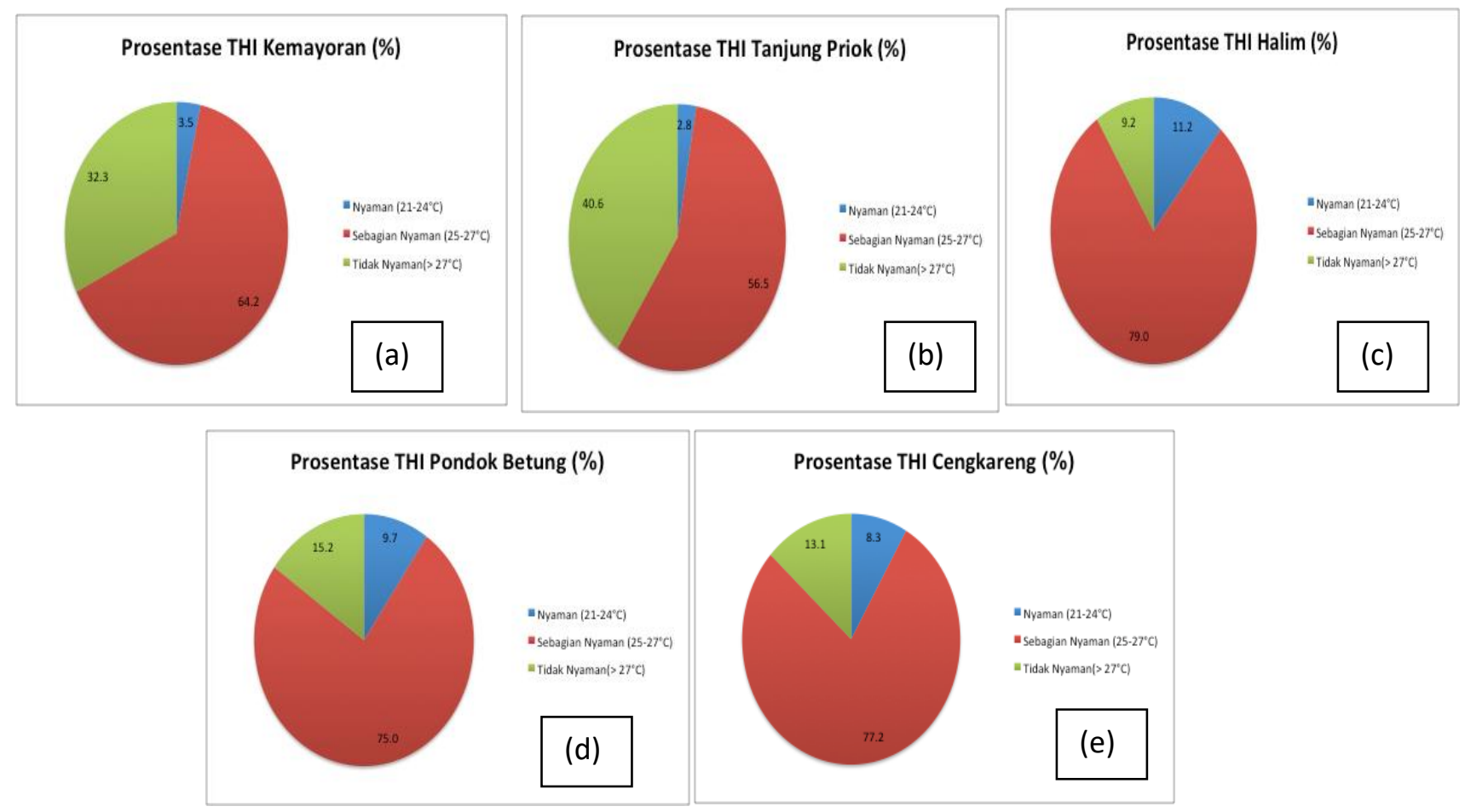

Gambar 3. Diagram Tingkat Kenyamanan di DKI Jakarta

Jakarta semakin berkembang lahan terbangun hingga hampir seluruhnya tertutup lahan urban.

Perubahan penggunaan lahan umumnya dipengaruhi oleh baik faktor alam seperti karakteristik geografis dan tanah dan faktor social ekonomi seperti pertumbuhan penduduk, perencanaan pembangunan, pengaturan penggunaan lahan, penzonaan dan peraturan lainnya yang terkait (Rustiadi et al , 2015). Perkembangan urbanisasi di DKI Jakarta telah memperluas konversi lahan subur dan lahan hijau di wilayah JaBoDeTaBek menjadi lahan terbangun (pemukiman, industry, layanan komersial dan lainnya).

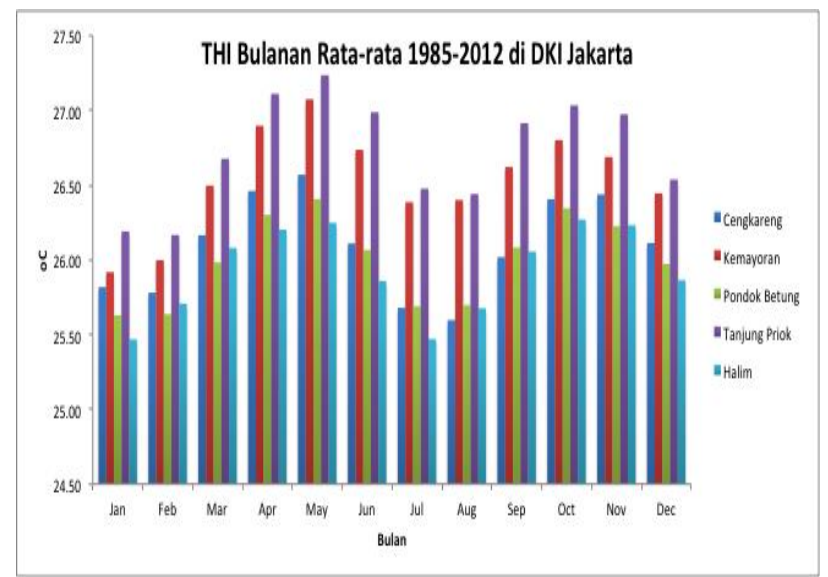

Gambar 4. Pola THI bulanan di DKI Jakarta

Perubahan penutupan lahan akan mengubah sifatsifat fisis permukaan seperti albedo, emisivitas, dan kekasapan permukaan yang berakibat mengubah panas yang diterima pada permukaan tersebut. Implikasinya adalah apabila suatu penutup lahan terkonversi dari lahan bervegetasi dan badan air menjadi menjadi daerah non vegetasi seperti pemukiman akan menyebabkan semakin meluasnya daerah panas dan kering. Apabila kondisi ini berlanjut akan menyebabkan tingkat kenyamanan akan berkurang menjadi tidak nyaman (Kalfuadi, 2009).
Manfaat penghitungan tingkat kenyamanan dapat digunakan sebagai pertimbangan untuk penambahan RTH dan Ruang terbuka air di (RTA) di kota DKI Jakarta. Menurut Effendy et al (2006), peningkatan RTH dan luas badan air berupa kolam, danau buatan, embung/situ dapat meredam peningkatan suhu, UHI dan THI. RTH dapat menurunkan suhu udara sekitar 5,68\% dan meningkatkan kelembapan udara sekitar 4\% (Asiani, 2007). 

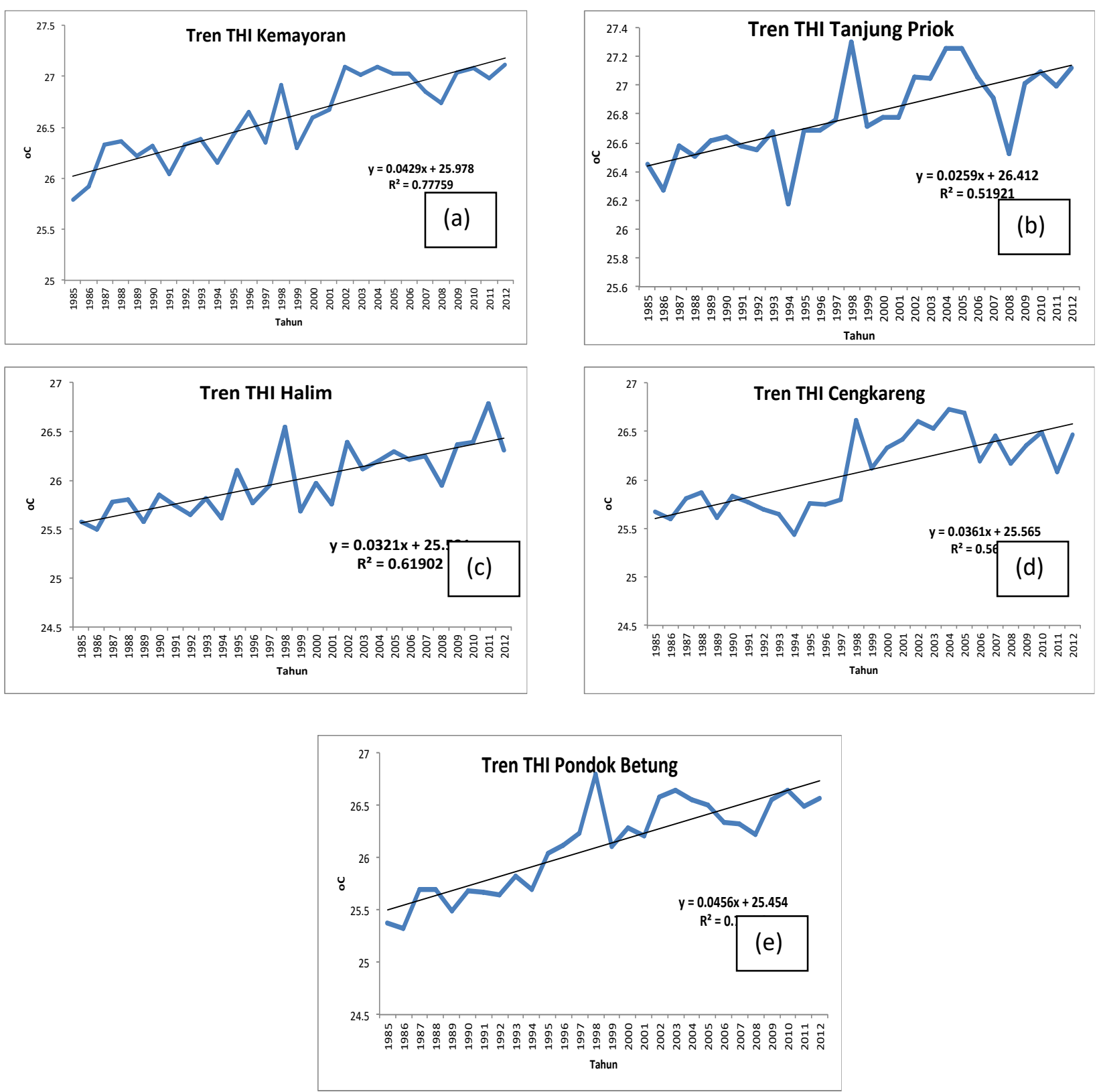

Gambar 5. Tren THI di DKI Jakarta

\section{Kesimpulan}

Berdasarkan data iklim periode 1985 - 2012 stasiun Kemayoran, Tanjung Priok, Halim, Cengkareng dan Pondok Betung, hasil penelitian menunjukkan rata-rata prosentase tingkat kenyamanan harian dengan kategori tidak nyaman sebesar 22,1\% (81 hari per tahun), sebagian nyaman $71 \%$ (259 hari per tahun) dan nyaman 7,1\% (26 hari per tahun). Tingkat kenyamanan menunjukkan semakin ke tengah kota semakin besar prosentase tidak nyaman. Selama periode 1985 - 2012 terjadi kecenderungan peningkatan indeks THI dengan signifikansi $>50 \%$ menunjukkan tingkat kenyamanan di DKI Jakarta yang cenderung semakin tidak nyaman.
Tren peningkatan THI di DKI Jakarta disebabkan akibat semakin meningkatnya perubahan penggunaan lahan menjadi lahan terbangun baik berupa pemukiman, industri, layanan komersial maupun perkantoran. Analisis THI di DKI Jakarta dapat dimanfaatkan sebagai pertimbangan penambahan RTH dan RTA di DKI Jakarta. Selain itu dapat digunakan juga sebagai pertimbangan dalam perancangan dan desain bangunan perkotaan yang menyesuaikan dengan kenyamanan manusia yang bermukim. 

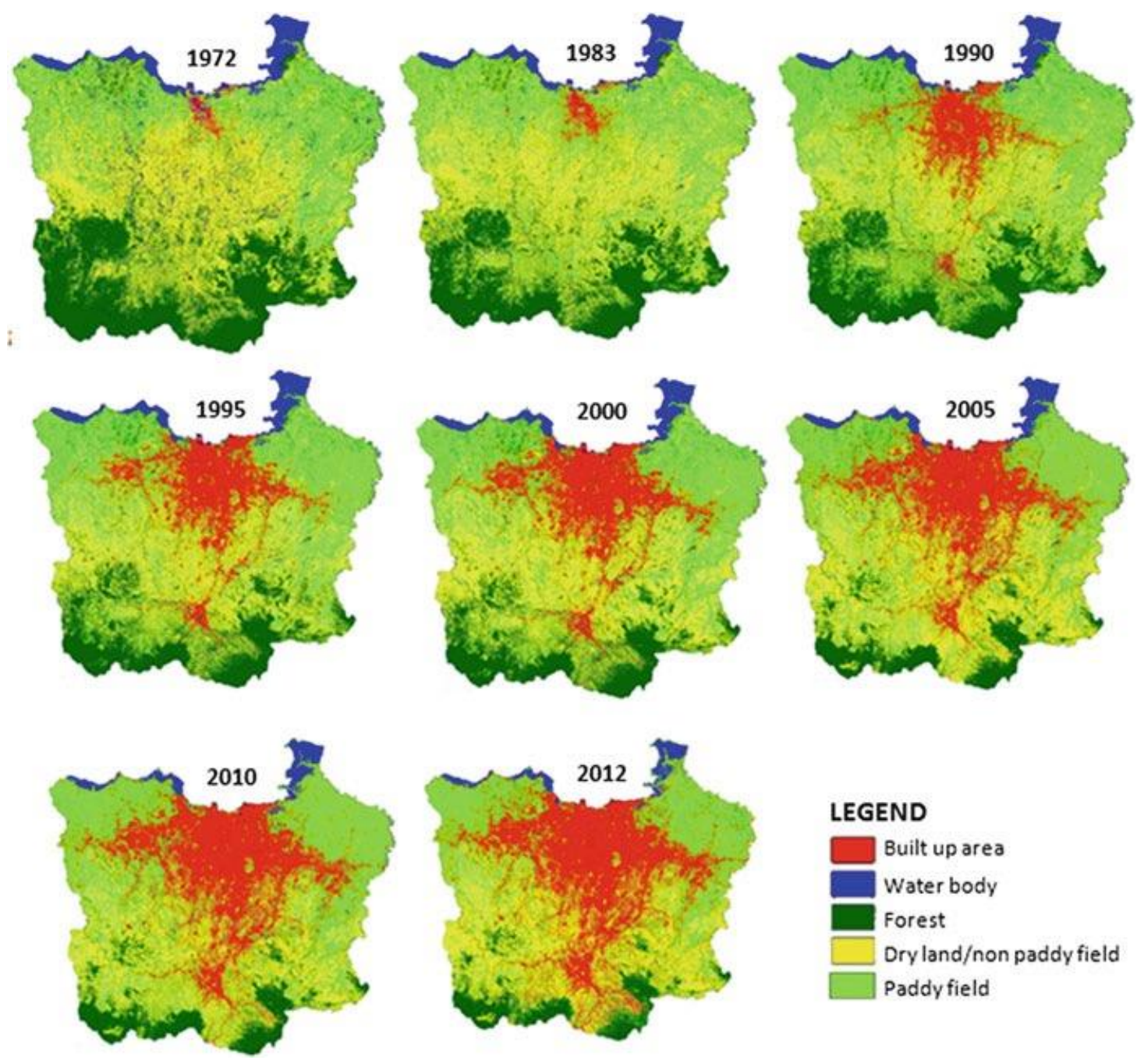

Gambar 6. Peta tutupan lahan JaBoDeTaBek tahun 1972 - 2012 (Rustiadi et al, 2015)

\section{Daftar Pustaka}

Asiani Y. (2007). Pengaruh kondisi ruang terbuka hijau (RTH) pada iklim mikro di Kota Bogor Tesis. Depok (ID): Universitas Indonesia.

Badan Pusat Statistik Provinsi DKI Jakarta. (2016). Jakarta dalam Angka 2016.

Effendy, S. (2007). Keterkaitan Ruang Terbuka Hijau dengan Urban Heat Island Wilayah Jabodetabek. Disertasi. Sekolah Pascasarjana IPB, Bogor.

Effendy S, Bey A, Zain AFM, Santosa I. (2006). Peranan ruang terbuka hijau dalam mengendalikan suhu udara dan urban heat island wilayah JABOTABEK. J Agrom Indones. 20(1):23-33.

Emmanuel, R. (1993). A hypothetical 'shadow umbrella'for thermal comfort enhancement in the Equatorial urban outdoors. Architectural Science Review, 36(4), 173-184.

Emmanuel, R., (1997). Summertime heat island effects of urban design parameters, Ph.D. Dissertation, University of Michigan, U.S.A.

Emmanuel R. (2005). Termal comfort implications of urbanization in a warm-humid city: The Colombo Metropolitan Region (CMR), Sri Lanka. J Build Environm. 40:1591-1601.
Honjo, T. (2009). Thermal comfort in outdoor environment. Global environmental research, 13(2009), 43-47.

Griffiths JF. (1966). Apllied Climatology. London (UK): Oxford University Pr.

Kalfuadi, Y. (2009). Analisis temperature heat index (THI) dalam hubungannya dengan ruang terbuka hijau (Studi Kasus : Kabupaten Bungo - Propinsi Jambi). Skripsi. FMIPA. IPB, Bogor.

Lakitan B. (2002). Dasar-dasar Klimatologi. Jakarta: Raja Grafindo Persada.

Lemke B, Kjellstrom T. (2012). Calculating workplace WBGT from meteorological data: a tool for climate change assessment. J Industr Health. 50: 267-278.

Maru, R., \& Ahmad, S. (2014). Daytime temperature trend analysis in the city of Jakarta, Indonesia. World Applied Sci. J, 32, 1808-1813.

Mayer, H. and P. Höppe. (1987). Thermal comfort of man in differ- ent urban environments. Theor. Appl. Climatol, 38: 43-49.

Mertens, E., (1999). "Bioclimate and city planning - open space planning," Atmospheric Environment, 33(2425): 4115-4123.

Nieuwolt S. (1977).Tropical climatology. London: Wiley;

Rushayati, S. B., \& Hermawan, R. (2013). Karakteristik kondisi urban heat island DKI Jakarta. Media konservasi, 18(2). 
Wati, T dan Fatkhuroyan. (2017). Analisis Tingkat Kenyamanan Di DKI Jakarta Berdasarkan Indeks THI (Temperature Humidity Index). Jurnal IImu Lingkungan, 15(1), 5763, doi:10.14710/jil.15.1.57-63

Rustiadi, E., Pribadi, D. O., Pravitasari, A. E., Indraprahasta, G. S., \& Iman, L. S. (2015). Jabodetabek Megacity: From City Development Toward Urban Complex Management System. In Urban Development Challenges, Risks and Resilience in Asian Mega Cities (pp. 421-445). Springer Japan.
Talaia, M., Meles, B., \& Teixeira, L. (2013). Evaluation of the Thermal Comfort in Workplaces-a Study in the Metalworking Industry. Occupational Safety and Hygiene, 473.

Thom, E. C. (1959). The discomfort index. Weatherwise, 12(2), 57-61. 